\title{
INTERDEPENDENCIES WITHIN THE SYSTEM OF OBJECTIVES OF A PRODUCT GENERATION IN INDUSTRIAL PRACTICE
}

\author{
Albers, Albert; Peglow, Natalie; Spadinger, Markus \\ Karlsruhe Institute of Technology (KIT)
}

\begin{abstract}
One challenge in product development is the megatrend of product individualization in the automotive supplier industry. Requirements for a variant by the customer may differ from those by the provider wherefore conflicting goals can arise. To cope with variant requests in the quotation phase systematically, a method to evaluate variants is necessary. Based on evaluation criteria the requirements from the stakeholders are valued. While evaluating, an already criterion can have an impact on assessing the remaining criteria. For this reason, the present investigation emphases the interdependencies between the evaluation criteria in industrial practice representing interdependencies within goals, requirements and boundary conditions in an early stage of product development. Analysing decisive factors supports to identify subsequent activities in the development process of a variant. Experts of an international automotive supplier developed impact matrices and a scenario technique tool is used to interpret the matrices. In context of the model of PGE - Product Generation Engineering, findings derive to ensure a comprehensive basis for decision-making concerning a variant-request.
\end{abstract}

Keywords: Variant management, Decision making, Evaluation, Early design phases, Design practice

Contact:

Albers, Albert

Karlsruhe Institute of Technology (KIT)

IPEK Institute of Product Engineering

Germany

albert.albers@kit.edu

Cite this article: Albers, A., Peglow, N., Spadinger, M. (2019) 'Interdependencies Within the System of Objectives of a Product Generation in Industrial Practice', in Proceedings of the 22nd International Conference on Engineering Design (ICED19), Delft, The Netherlands, 5-8 August 2019. DOI:10.1017/dsi.2019.124 


\section{INTRODUCTION}

Due to the increasing product individualization, systematic variant management is gaining in importance to react in a targeted manner to customer-specific variant requests in the quotation phase. With view to the provider, variants can lead both to an immense resource effort and to an increased customer satisfaction. Above all, adjustments to the production and validation processes within the current product development of a product generation can emerge. Conflicts of objectives can result between the requirements of the customer and the provider. For this reason, it must already be checked in an early stage of variant implementation whether the goals, the requirements and the boundary conditions from both parties for a variant are consistent with each other. Among others, an available manufacturing concept as well as an existing testing concept of a product generation determine the decision to quote and to implement a variant. Besides the effects on the technical systems, a variant may add value regarding the business strategy. Therefore, an overall assessment of the effects is useful to decide about a customer-specific variant. Evaluation criteria within the quotation phase of variants support to evaluate the consistency regarding the requirements. During the evaluation, a mutual influence between the evaluation criteria is inevitable. To identify next steps in the development process of a variant, the present investigation focuses on the analysis of interdependencies between defined evaluation criteria as well as on identifying decisive factors. In this sense, experts developed impact matrices. A scenario technique tool supports in interpreting the matrices. Levers with the most impact derive of the analysis which enforce a comprehensive and consistent evaluation of variants in context of the model of PGE - Product Generation Engineering.

\section{STATE OF THE ART}

\subsection{Variant management in an early phase of product development}

The research field of variant management deals with the design, the management and the control of planned and unplanned variants in a company (Heina, 1999). The aim is to determine an optimal costbenefit ratio of the variety of variants (Rathnow, 1993). The number of planned variants is already defined within the development of a product, whereas unplanned variants are included in the product range due to increasing market pressure or customer-specific requirements (Heina, 1999). In addition to the positive effects of variants from a customer and provider perspective, the negative effects can be seen above all in form of increasing complexity in areas such as development, production and services (Kersten, 2002). Therefore, a target-oriented handling of variants reflects an essential potential in context of a successful product life cycle (Raubold, 2011). As a result, decision making has an immense impact on all phases of the product development process. Especially in an early stage, the specification of the product architecture is an important decision which has effects on the product design and subsequent processes of product development. In this context, decision making models are used to provide insight into and support for decision making situations. (Seram, 2013)

Traditional methods for evaluation of product ideas are reaching their limits in the early phase of product development which is characterized by uncertainties and vague information. For example, manufacturability evaluation is subject to an uncertain and vague decision making process. As a result, a fuzzy decision model for manufacturability evaluation was developed which takes the multi-level and multi-goal requirements of manufacturing into account. (Jiang and Hsu, 2003) Due to a complex, uncertainty-affected and interdisciplinary product development, objectives have to be specified continuously during the development process. To deal with highly networked and dynamic objectives systematically, the degree of maturity, the degree of rigidity, the leverage and the impact are objective dimensions for characterizing them. (Albers et al., 2011) In a literature review, Seram (2013) identified existing decision making tools and methods which he categorized according to their purpose. The Analytic Hierarchy Process (AHP) can be used to select suitable design solutions and the Analytic Network Process (ANP) can be used for product concept evaluation (Seram, 2013). The AHP supports the selection of different action alternatives with the help of defined evaluation criteria based on a multilevel hierarchic structure. The further developed ANP takes into account the dependencies of a decision network. (Saaty and Vargas, 2006) The utility value analysis is another method for structuring complex decision problems (Kühnapfel, 2014). Due to a reasearch project, Kihlander and Ritzen (2009) analysed the differences between the methods developed in theory and those applied in 
practice within the concept evaluation. Among other things, he states that mainly one concept is developed in practice. Methods in theory usually focus on the evaluation of several alternatives. (Kihlander and Ritzen, 2009) To investigate different scenarios of one concept, scenario technique tools are useful to analyse either potential future events based on a concrete status quo or potential future development trends based on concrete future events (Gausemeier et al., 1996). For example, the Scenario-ManagerTM 2013 serves to structure scenario fields systematically and to identify areas of influence while analysing impact matrices in a targeted manner. (Fink and Siebe, 2013) Based on indicators, a proposal of key factors may be derived which need to be discussed in a subjective selection process with the scenario team. In this context, key factors are a subset of the factors investigated with high relevance for the overall system. Indicators include the activity as the sum of the row values and illustrates the effect of a factor on all other factors. In contrast, passivity is the sum of the column values and describes how strong a factor is influenced by the others. The dynamic index is the product of activity and passivity and suggests the degree of networking of a factor in the entire system. The proactivity index is the quotient of activity and passivity and represents the degree of a factor's leverage. (Fink et al., 2002)

\subsection{Product development in context of PGE - product generation engineering}

With regard to the entire organization, the development process of a new product generation can be modelled by the process model iPeM - integrated product development model (Albers et al., 2016a). Each of the (technical) systems (including further product generations, validation system, production system, strategy) are mapped in a layer of the iPeM. The basis for the iPeM is the system triple (Ropohl, 1975) (system of objectives, operation system, systems of objects). The operation system (including resources, methods, activities, etc.) transfers the objectives, the requirements, the boundary conditions and their independencies within the system of objectives into the systems of objects. (Albers et al., 2016a) All results generated in the development process, such as drafts, prototypes and above all the final product, are elements of the system of objects of the respective layer. The assignment of an element to the respective system of the system triple depends on the perspective view knowing the time, the purpose and the position of the observation (Meboldt, 2008). The model of PGE combines two core theses. On the one hand, every development of a new product generation is based on the combination of carryover variation $(\mathrm{CV})$, embodiment variation $(\mathrm{EV})$ and principle variation (PV), whereby the sum of GV and PV defines the share of new development. On the other hand, each product generation is developed based on reference products. (Albers et al., 2016b) Accordingly, in context of PGE, variants are product generations characterized, among other things, by a high share of CV (Peglow et al., 2017) which may include adjustments on existing technical systems. In the Early Phase of PGE an initial system of objectives is defined that implies the description of the customer, user and provider benefits in a product profile as well as an initial evaluation of the product profile (Albers et al., 2018). The quotation phase includes the identification of risks, the selection of lucrative projects and the overall cost calculation (Alfen et al., 2013). In context of variant management, the quotation phase in the automotive supplier industry is a specific Early Phase of PGE which begins with the request for quotation by the customer and ends with the submission of quotation by the supplier (Walch and Albers, 2014, Albers et al., 2018) (Figure 1). As a result of a previous knowledge exchange, an initial system of objectives of the product generation can be already defined at the time of request for quotation.

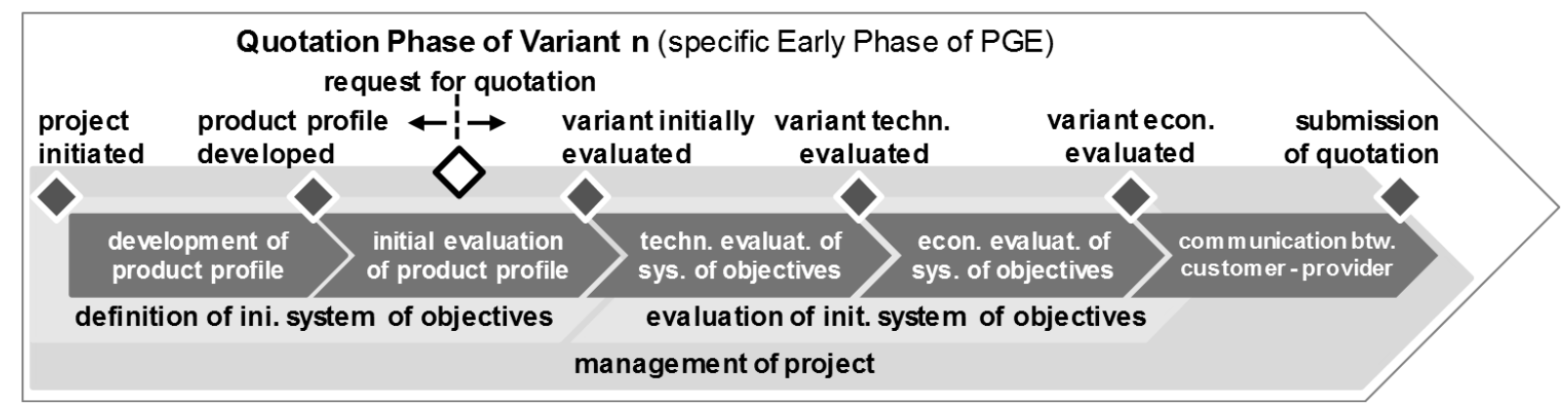

Figure 1: Quotation phase of variants in PGE - product generation engineering 
A technical and economic evaluation is available for submission of quotation. The aim is to check the consistency of the system of objectives containing objectives, requirements, boundary conditions and their interdependencies postulated by the customer and the provider. When dealing with a highly dynamic development environment, the evaluation process is subject to a project-specific degree of flexibility. (Peglow et al., 2019) The concrete system of objectives is the basis for the product specification.

\section{PRELIMINARY WORK}

The present investigation bears on existing research activities with an international automotive supplier of high-pressure pumps representing an implementation of the meta-model iPeM (chap. 2.2). To evaluate customer-specific variants within the quotation phase (chap. 2.2), a systematics including an evaluation process and a method for evaluation is developed. Five evaluation elements $(i=1,2,3,4,5)$ are defined to check the consistency of the requested variant with the corresponding elements available at that time (product strategy, product design, testing concept, manufacturing concept, procurement concept). Each element belongs to a layer of the iPeM and form, inter alia, together the system of referenced elements. Due to the evaluation process, experts evaluate the time-independent evaluation elements product strategy and product design firstly. Depending on the customer-specific variant, the steering committee decides about the selection of further variable evaluation elements (testing concept, manufacturing concept, procurement concept). Accordingly, experts examine the chosen combination, whereby the evaluation is time-independent. (Peglow et al., 2019) The evaluation elements are among others characterized by the same method for evaluation with element-specific manifestations. In total, the evaluation is based on 30 defined evaluation criteria. Of these, six $(\mathrm{j}=1,2,3,4,5,6)$ belong to each evaluation element. Exemplarily, the technical evaluation elements consider the (technical) realization effort. With regard to the manufacturing concept, the criterion focuses on the manufacturing technology. Concerning the testing concept, the criterion refers the testing and measuring technology. For all $\mathrm{i}=1-5$, experts rank the effects for $\mathrm{j}=1-5$ on a 4-point ordinal scale (very low, low, high, very high) and recommend the variant $(\mathrm{j}=6)$ with a binary decision. All 30 are included in the calculation of the Effect Estimation Factor. (Albers et al., 2019) Considering the weighting of each evaluation element and of each evaluation criterion, the calculated factor illustrates the comprehensive effect of a variant for the company. An EEF-value of 100\% represents a high potential and $0 \%$ no potential to implement a variant.

\section{AIM OF RESEARCH AND METHODOLOGY}

In numerous literature, systems of objectives with the associated objectives, requirements and boundary conditions for the product development process were investigated. In addition, methods and tools exist to support the early phase of product development (Seram, 2013). With the help of the iPeM based on the system triple, a consistent system of objectives is described in context of the model of PGE (Albers $e t$ al., 2016a). Within the variant management in the quotation phase of an international automotive supplier of high-pressure pumps, it is particularly important to evaluate the consistency of the system of objectives of a new variant including the elements available at that time (chap. 3). Due to political or economic conditions, customer requirements may change over time. Hence, it is difficult to determine the effects on the system of referenced elements while developing a new product generation. Therefore, the calculation of the EEF (chap. 3) depends on the customer-specific variant in future. To realize a uniform evaluation, the evaluation criteria describe elements of the system of objectives of a requested variant. Within the mentioned automotive supplier, the present investigation focuses on the interdependencies between the evaluation criteria in the quotation phase and on identifying the relevant criteria within the decision on implementing a variant. For this reason, the following research questions are:

- Which interdependencies exist within the system of objectives of a variant in the quotation phase of high-pressure pumps and which proposals of key factors result from the direct impact matrix of the variant evaluation?

- Which proposal of key factors transpires from the derived indirect impact matrix provided by a scenario technique tool?

- Which key factors are selected finally and which findings can be deduced in context of the model of PGE? 
To answer these questions, the variant management in the quotation phase was examined. The first question is answered by impact matrices which were developed with experts from various departments $(\mathrm{n}=17)$ including managers of the middle management. The experts were involved in the development of the systematics (chap. 3) and have cross-functional knowhow within the variant management. A mean value matrix consolidates the expert-matrices which maps the interdependencies of the criteria for the evaluation of variants. Based on this direct mean value matrix, indicators were calculated and proposals of key factors are derived which have a decisive relevance for the evaluation of variants in context of the overall system. The second research question is answered with the help of the software tool Scenario-ManagerTM. Basis for the analysis is the mean value matrix, whereby the tool generates an indirect impact matrix and a proposal of key factors. For the third research question, a manager supports in discussing the results and in selecting the key factors proposed by the authors. The findings are examined in context of the model of PGE.

\section{INTERDEPENDENCIES WITHIN THE SYSTEM OF OBJECTIVES OF VARIANTS IN THE QUOTATION PHASE}

\subsection{Direct impact matrix within the evaluation of variants}

To evaluate variants of high-pressure pumps in the quotation phase within an international automotive supplier, five existing evaluation elements (in the following: elements) ( $i=1,2,3,4,5)$ of the product generation with each six evaluation criteria $(j=1,2,3,4,5,6)$ need to be considered (chap. 3). To determine the direct influence of an evaluation criterion on another, experts $(n=17)$ worked out impact matrices. The experts assessed the influence of a vertically listed criterion on a horizontally listed criterion. With regard to the selected scale, +2 or +1 indicates that the vertical criterion has a very strongly or strongly positive influence on the horizontal criterion. In contrast -2 or -1 means a very strongly or strongly negative influence and 0 no influence at all. These individual matrices were consolidated into an overall matrix (Table 1) which shows the mean value for each matrix entry. For the sake of clarity, the mean values of the matrix entries are rounded values while the calculations are based on the exact values. In contrast to the impact matrix according to Arnold (2015), the selected scale takes the differentiation between a positive and negative influence into account. Besides the identification of a proposal for key factors based on indicators, the differentiation allows a second proposal based on the calculated impact on the Effect Estimation Factor (EEF) (chap. 3). Due to the chronological evaluation sequence of the elements (chap. 3), the influence within the light grey coloured cells are not determined. Assuming that an evaluation criterion cannot influence itself, the grey diagonal does not allow an entry.

The first proposal of key factors includes the evaluation of the consolidated direct impact matrix by using the amounts of the matrix entries. For each evaluation criterion, the indicators of the scenario analysis (activity, passivity, dynamic index, proactivity index) are calculated (chap. 2.1). Using the example of $\mathrm{i}=1, \mathrm{j}=1$, the calculations are explained. The activity (exact: 13,7) is the sum of the entire row: $1+2+1+0,6+0,2+0,2+0,6+1,4+1+0,7+0,3+0,7+0,7+1+0,4+0,2+0,2+0,4+0,3+0,3+0,3=13,5$. The passivity (exact: 6,0 ) is the sum of the entire column: $1+2+1+1+1=6,0$. The dynamic index (exact: 82 ) is the product and the proactivity index (exact: 2,3 ) is the quotient of activity $(13,7)$ and passivity $(6,0)$. After consultation with a manager of middle management coordinating the international production network, ten $(33,3 \%)$ of 30 evaluation criteria were set as the maximum number to derive the key factors from. Based on the key factor selection procedure according to Fink et al. (2002), a total of roughly $50 \%$ are definite based on the dynamic index (5). The other five result from the activity (2), the passivity (1) and the proactivity index (2). The final proposal results in coordination with this manager as representative of the scenario team. In accordance to Fink and Siebe (2013), the selection criteria are: avoidance of duplication of content, ensuring topic coverage, completeness of range of topics, consideration of political factors (concerning the business policy) and acceptance of the scenario team. The indicators of the identified key figures have dark grey coloured cells.

The second proposal comprises the influence from an evaluation criterion on the EEF (chap. 3) by taking into account the plus/minus signs of the matrix entries. In this context, the scaling direction of the 4-point ordinal scale (chap. 3) of the evaluation criterion need to be noticed. For $i=1, j=1-5$ and in each case of $\mathrm{j}=6$, the criterion is positively scaled in ascending order. 
Table 1: Mean value matrix resulting of the direct impact analysis

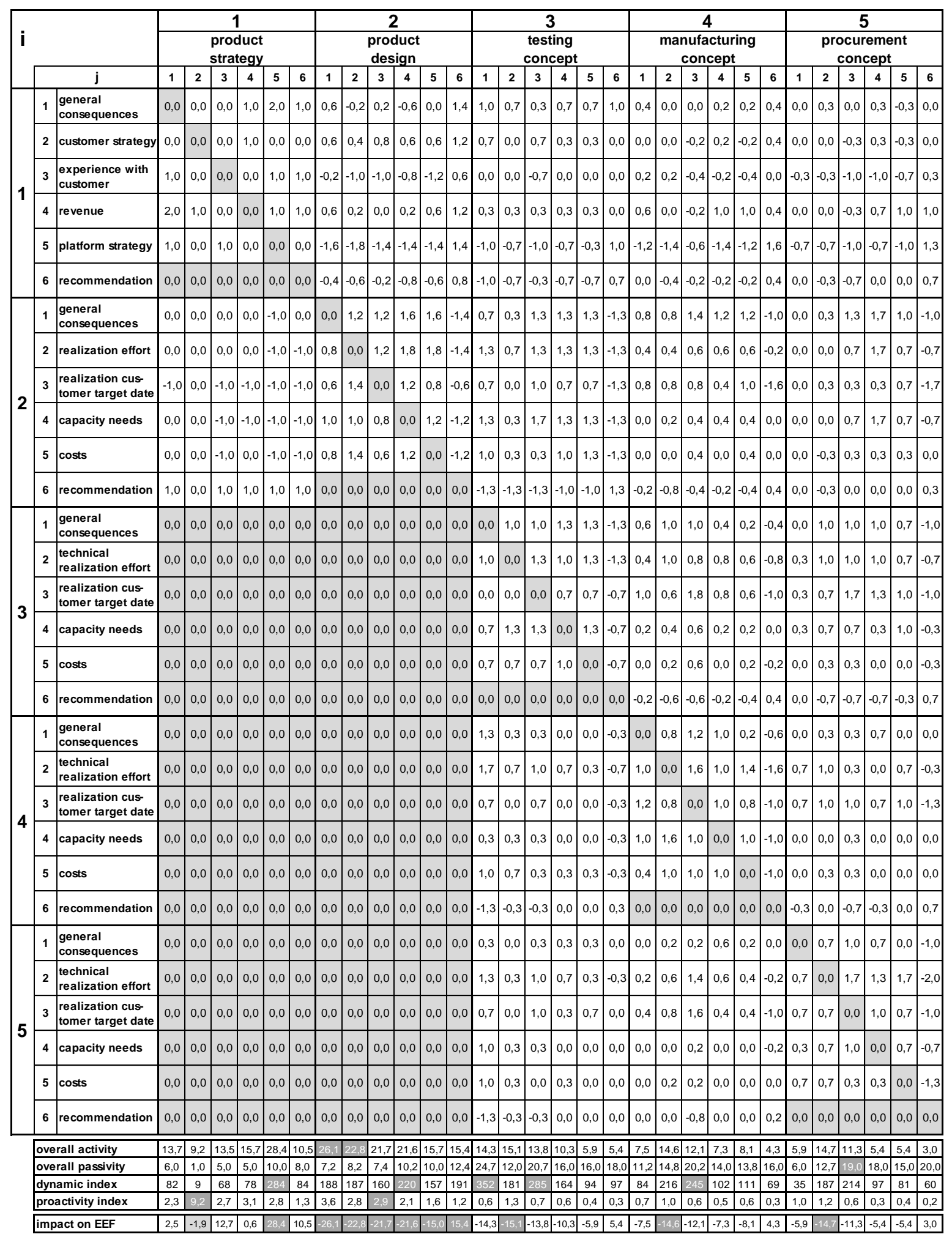

This means that the highest value of the evaluation criterion implies a positive effect. Therefore, +2 or +1 illustrates a positive and -2 or -1 a negative overall impact on the EEF (unchanged plus/minus sign). In contrast, for $i=2-5, j=1-5$, the criterion is scaled in ascending negative order. This means that the highest value implies a negative effect. Accordingly, +2 or +1 illustrates a negative and -2 or -1 a positive overall impact on the EEF (reversed plus/minus sign). For example, the influence of the technical realization effort within the procurement concept $(i=5, j=2)$ is estimated as $+1,4$ on the realization of the customer target date within the manufacturing concept $(i=4, j=3)$. Due to the ascending positive scaling of the EEF (chap. 3 ), the evaluation criterion $i=5, j=2$ has a negative overall 
impact on the EEF. Thus, the plus/minus sign needs to be reversed. Using the example of $i=5, j=2$ considering the plus/minus signs, the impact on the EEF is the sum of the entire row: -1,3-0,3-1,0-0,7$0,3-0,3-0,2-0,6-1,4-0,6-0,4-0,2-0,7-1,7-1,3-1,7-2,0=-14,7$. The evaluation criteria with the highest amount determine the result of the EEF calculation decisively. It can be seen that the ten criteria with the greatest impact on the EEF (dark grey cells) are not the same as the key factors that were identified in the first proposal based on the indicators. It is also striking that customer strategy $(i=1, j=2)$ has a negative overall impact on the EEF which is a contradiction to the ascending positive scaling. One possible reason is that the influence of the element product strategy (i=1) was interpreted differently by the experts during the development of the matrices. Own observations confirm this explanation owing to joining the expert interviews.

\subsection{Indirect impact matrix within the evaluation of variants}

To depict the indirect relations between the evaluation criteria, the software tool ScenarioManagerTM from ScIM supports by automatically generating an indirect impact matrix based on the direct matrix. The mean value matrix (Table 1) was imported into the tool, whereby each matrix entry was previously transferred to the amount of the value. Therefore, the plus/minus signs of the matrix entries are ignored. Due to the consideration of the plus/minus signs and the simplification in practice, the selected scale with the amounts of the rounded values $(0,1,2)$ (chap. 5.1) differs from the proposed scale of the scenario analysis $(0,1,2,3)$ (Arnold, 2015) by not assigning the value 3 . As a result of the indirect analysis, the 30 evaluation criteria are presented in an Activity-Passivity-Grid generated by the ScenarioManagerTM (Figure 2).

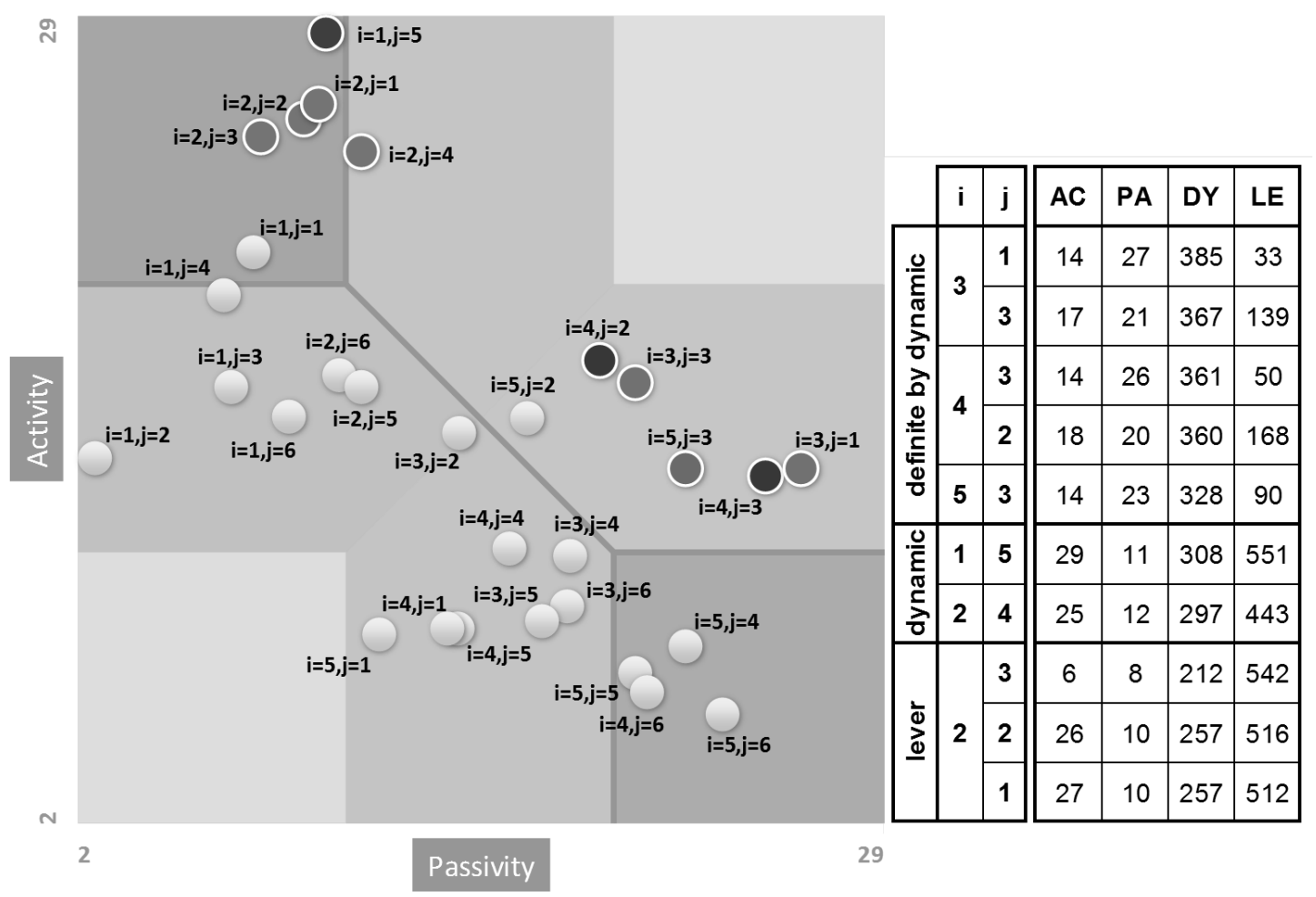

Figure 2: Activity-Passivity-Grid generated by the ScenarioManagerTM

The activity is compared to the respective passivity in absolute values with a defined form of representation (Fink et al., 2002). Based on the indirect impact matrix, the tool calculates the activity (AC), passivity (PA), dynamic (DY) and lever (LE) (chap. 2.1). Furthermore, the tool proposes key factors which support subsequent discussion with experts. The proposed key factors are coloured in the Activity-Passivity-Grid and the respective indicators are listed in the table. With regard to the uniformity to chapter 5.1, a maximum of 10 was set. Based on the dynamic, the number of definite (5) and possible (2) key factors was determined in consultation with the manager of the middle management (chap. 5.1). Moreover, the amount of three was defined as the amount of possible key factors depending on the lever. It can be seen that the proposed selection differs from the proposals 
identified in chap. 5.1. A possible reason is the consideration of indirect relations. A further reason may be the expert-based distribution of the amount to the calculated indicators.

\subsection{Findings in context of the model of PGE - product generation engineering}

As a result of the different proposals, a key factor selection is made and proposed by the authors which is discussed with the manager of the middle management (chap. 5.1) (Table 2). The table includes the proposed key factors from the analysis of the direct impact matrix (chap. 5.1) based on the calculated indicators (1. proposal) and the overall impact on the EEF (2. proposal). Furthermore, the table comprises the proposal of the analysis of the indirect impact matrix (chap. 5.2) based on the calculated indicators (3. proposal). The selection criteria (chap. 5.1) (Fink and Siebe, 2013) justify the respective decision and match up to the objective dimensions (chap.2.1) (Albers et al., 2011). This approach enforces the subjective selection process (Gaßner and Steinmüller, 2009) which can possibly differ to a selection in other companies.

Table 2: Comparison and selection of the proposed key factors

\begin{tabular}{|c|c|c|c|c|c|c|}
\hline & \multicolumn{2}{|c|}{ chap. 5.1. } & \multirow{2}{*}{$\begin{array}{l}\text { chap. } 5.2 \\
\text { 3. proposal }\end{array}$} & \multirow[b]{2}{*}{ selection criterion } & \multirow[b]{2}{*}{ objective dimension } \\
\hline $\mathbf{i}$ & j & 1. proposal & 2. proposal & & & \\
\hline \multirow{2}{*}{1} & 2 & $\checkmark$ & & & political factor (business policy) & degree of rigidity \\
\hline & 5 & $\checkmark$ & $\checkmark$ & $\checkmark$ & consistent proposal & impact \\
\hline \multirow{6}{*}{2} & 1 & $\checkmark$ & $\bar{\checkmark}$ & $\checkmark$ & consistent proposal & impact \\
\hline & 2 & $\checkmark$ & $\checkmark$ & $\checkmark$ & acceptance of scenarioteam & degree of rigidity \\
\hline & 3 & $\checkmark$ & $\checkmark$ & $\checkmark$ & consistent proposal & leverage \\
\hline & 4 & $\checkmark$ & $\checkmark$ & $\checkmark$ & acceptance of scenarioteam & degree of rigidity \\
\hline & 5 & & $\checkmark$ & & & \\
\hline & 6 & & $\checkmark$ & & & \\
\hline \multirow{3}{*}{3} & 1 & $\checkmark$ & & $\checkmark$ & & \\
\hline & 2 & & $\checkmark$ & & & \\
\hline & 3 & $\checkmark$ & & $\checkmark$ & completeness of range of topics & degree of maturity \\
\hline \multirow{2}{*}{4} & 2 & & $\checkmark$ & $\checkmark$ & acceptance of scenarioteam & degree of rigidity \\
\hline & 3 & $\checkmark$ & & $\checkmark$ & completeness of range of topics & degree of maturity \\
\hline \multirow{2}{*}{5} & 2 & & $\checkmark$ & & & \\
\hline & 3 & $\checkmark$ & & $\checkmark$ & completeness of range of topics & degree of maturity \\
\hline
\end{tabular}

The findings in industrial practice described below illustrate the conclusions in context of PGE. The element product design has the largest leverage and impact on the EEF (chap. 5.1).

In comparison to the other four considered elements $(\mathrm{i}=1,3,4,5)$, the element product design $(\mathrm{i}=2)$ has the largest calculated activity, dynamic index and proactivity index which reflect the highest leverage and connection. The impact on the EEF confirms the result. Due to this, it can be assumed that the element product design has a dominant role within the evaluation of variants in the quotation phase.

The element product design has the largest amount of identified key factors.

This result illustrates the impact of the several evaluation criteria regarding the product design of a variant. Furthermore, it shows the relevance of the element product design (i=2) in the overall system which confirms the dominant role of the element product design.

The evaluation criterion customer strategy of the element product strategy is selected from a political (business policy) point of view (chap. 5.1).

With the political choice (concerning the business policy) of the evaluation criterion customer strategy, the importance of the corporate strategy becomes apparent. The satisfaction of customer needs plays an important role for the company, although this was only suggested in one proposal. This is the reason why the degree of rigidity is the directed objective dimension. Among other things, the implementation of variants depends on the strategic orientation of the company. Therefore, it is necessary to evaluate the effects of a variant on not only the technical systems, but also to include the product strategy. Hence, the calculation of the EEF comprises the evaluation of efforts as well as of benefits of a customer-specific variant (chap. 3 ).

The evaluation criterion customer due date is defined as key factor for all technical elements.

To complete the range of topics, the criterion customer due date is selected for the elements product design, testing concept, manufacturing concept and procurement concept $(\mathrm{i}=2,3,4,5)$. Therefore, the customer goals are represented in all (technical) elements to be evaluated. This affirms the degree of 
maturity of customer orientation in the quotation phase of variants. Consequently, the focus within the provider's value chain is on the product profile (chap. 5.1) which covers both the provider benefits and the customer and thus also the user benefits.

\section{The evaluation criterion technical realization effort of the element manufacturing concept is} selected due to intended acceptance.

From its existence, the manufacturing concept is of decisive importance for the analysed company. Because of this, the scenario team favoured the selection of the criterion technical realization effort within the element manufacturing concept $(\mathrm{i}=4)$ which represents a high degree of rigidity.

The elements testing concept, manufacturing concept and procurement concept have the greatest passivity (chap. 5.1).

Regarding the chronological sequence of the evaluation process, the technical elements $(i=3,4,5)$ are influenced by the elements product strategy $(\mathrm{i}=1)$ and product design $(\mathrm{i}=2)$. Moreover, the calculations of passivity (chap. 5.1) show that the element testing concept, manufacturing concept and procurement concept are also strongly influenced by the evaluation of each other.

Regarding the variant-specific resource effort, the share of new development of a variant, inter alia, determines the evaluation process and therefore the evaluation result of the mentioned elements $(\mathrm{i}=1,2,3,4,5)$ (chap. 3). In context of PGE, knowledge about, among other things, the referenced product features, product structure rules, processes and methods should be accessible for all involved stakeholders in a documented form within the system of objectives of the observed variant. By means of a consistent system of objectives, a transparent knowledge base and a solution space based on the system of referenced elements ensure a proper evaluation of the variant using the EEF-calculation and support to identify appropriate alternatives for action. For this reason, it is indispensable to have insight into the provider's and customer's objectives, requirements, boundary conditions as well as their interdependencies. According to the given investigation, it may be assumed that the variation of a product can imply adjustments to the referenced validation system and production system (chap. 3). Due to the systematics to differentiate variants in context of PGE (chap. 2.2), the varied technical systems can be seen each as a variant of the related validation system and production system with a high share of carryover variation. If there may be adjustments to the strategy, further research is necessary how to describe the variations of the iPeM-layer strategy. Concluding, the variants of the (technical) systems play a determining role in shaping the system of referenced elements.

\section{SUMMARY AND OUTLOOK}

The investigation presents the modelling of a system of objectives using exemplarily the evaluation of variants in the quotation phase of an international automotive supplier. An impact matrix shows the interdependencies of defined evaluation criteria, which experts evaluate concerning the consistency of a variant and the existing elements of the system of referenced elements. Based on the developed direct and the derived indirect impact matrix, three proposals of key factors result from calculating indicators of scenario technique and the impact on the EEF. The proposed key factors are discussed with a manager of the middle management and ten evaluation criteria are selected using selection criteria (Fink and Siebe, 2013) and assigning to objective dimensions (Albers et al., 2011). Findings derive in context of the model of PGE. Among others, the element product design plays a dominant role in the decision on implementing a variant. Regarding the value chain, the provider attaches great emphasis on the customer benefit. The elements testing concept, manufacturing concept and procurement concept are most influenced by the others in the evaluation process. The analysis is carried out at an international automotive supplier for high-pressure pumps. In total 17 experts developed individual impact matrices which are subject to a subjective assessment. The key factors are identified with the help of a subjective selection process. To evaluate the findings, additional use cases, more impact matrices as well as further expert opinions in the selection process need to be analysed. Ongoing research focuses on the applicability and the transferability of the evaluation criteria. In context of the model of PGE, research needs concerning the development of the system of referenced elements and the development of system generations are identified. In addition, further research bears on the implementation of the systematics to evaluate variants and the emerging application evaluation in industrial practice. In conclusion, interdependencies exist within the system of objectives of a variant in the quotation phase and the scenario technique is a useful and supporting method to model them. 


\section{REFERENCES}

Albers, A., Lohmeyer, Q. and Ebel, B. (2011), "Dimensions of objectives in interdisciplinary product development projects", 18th International Conference on Engineering Design (ICED11), Copenhagen, Denmark.

Albers, A., Reiß, N., Bursac, N. and Richter, T. (2016a), “The integrated product engineering model (iPeM) in context of the product generation engineering", 26th CIRP Design Conference, Stockholm, Sweden.

Albers, A., Bursac, N. and Rapp, S. (2016b), "PGE - Product generation engineering - Case study of the dual mass flywheel", International Design Conference - Design 2016, Dubrovnik, Croatia.

Albers, A., Heitger, N., Haug, F., Fahl, J., Hirschter, T. and Bursac, N. (2018), "Supporting Potential Innovation in the Early Phase of PGE - Product Generation Engineering: Structuring the Development of the Initial System of Objectives", R\&D Conference 2018, Milan, Italy.

Albers, A., Rapp, S., Peglow, N., Heimicke, J., Spadinger, M. and Wattenberg, F. (2019), “A Basis for Project Planning in PGE - Product Generation Engineering: Variations as Activity Patterns”, 30th CIRP Design Conference, Povoa de Varzim, Portugal, accepted.

Alfen, H.W., Bauer, T., Bodenmüller, E., Brezinski, H., Brömer, K., Grove, N., Güther, P., Jacob, D. and Oepen, R.-P. (2013), “Ökonomie des Baumarktes Grundlagen und Handlungspositionen: Zwischen Leistungsversprecher und Produktanbieter", B. Bau (ed.), Springer Vieweg.

Arnold, B. (2015), "Prognose von Schlüsselqualifikationen von IT-Serviceunternehmen. Ein umfeldorientierter Blick auf das Jahr 2015”, Picot, A., Reichwald, R., Franck, E. (eds.), Deutscher Universitäts-Verlag, Wiesbaden.

Fink, A. and Siebe, A. (2013), "Scenario-ManagerTM 2013 Quick Start”, ScMI (ed.).

Fink, A., Schlake, O. and Siebe, A. (2002), "Erfolg durch Szenario-Management: Prinzip und Werkzeuge der strategischen Vorausschau", Campus Verlag, Frankfurt.

Gaßner, R. and Steinmüller, K. (2009), "Welche Zukunft wollen wir haben? Visionen, wie Forschung und Technik unser Leben verändern sollen”, WerkstattBericht Nr. Vol. 104, Institute for Future Studies and Technology Assessment (ed.), Berlin.

Gausemeier, J., Fink, A. and Schlake, O. (1996), "Szenario-Management Planen und Führen mit Szenarien", Carl Hanser Verlag, München, Wien.

Heina, J. (1999), "Variantenmanagement Kosten-Nutzen-Bewertung zur Optimierung der Variantenvielfalt”, Gabler Edition Wissenschaft.

Jiang, B.C. and Hsu, C.-H. (2003), "Development of a fuzzy decision model for manufacturability evaluation", Journal of Intelligent Manufacturing, Vol. 14.

Kersten, W. (2002), "Vielfaltsmanagement: Integrative Lösungsansätze zur Optimierung und Beherrschung der Produkte und Teilvielfalt", Wildemann, H. (ed.), TCW-Report.

Kihlander, I. and Ritzen, S. (2009), "Deficiencies in Management of the Concept Development Process: Theory and Practice", 17th International Conference on Engineering Design (ICED09), Palo Alto, USA.

Kühnapfel, J.B. (2014), "Nutzwertanalysen in Marketing und Vertrieb", Springer Gabler, Wiesbaden.

Meboldt, M. (2008), "Mentale und formale Modellbildung in der Produktentstehung - als Beitrag zum integrierten Produktentstehungs-Modell (iPeM)", Forschungsberichte, Albers, A. (ed.), Vol. 29, Universität Karlsruhe.

Peglow, N., Powelske, J., Birk, C., Albers, A. and Bursac, N. (2017), "Systematik zur Differenzierung von Varianten im Kontext der PGE - Produktgenerationsentwicklung”, Tagungsband 15. Gemeinsames Kolloquium Konstruktionstechnik, Düsseldorf, Germany.

Peglow, N., Heimicke, J. and Albers, A. (2019), “Agiler Bewertungsprozess in einer variantenreichen PGE Produktgenerationsentwicklung”, Vol. 5. Stuttgarter Symposium für Produktentwicklung (SSP): Agilität und kognitives Engineering, Stuttgart, Germany, accepted.

Rathnow, P.J. (1993), “Integriertes Variantenmanagement: Bestimmung, Realisierung und Sicherung der optimalen Variantenvielfalt”, Vandenhoeck \& Ruprecht.

Raubold, U. (2011), “Lebenszyklusmanagement in der Automobilindustrie Ein Optimierungsansatz auf Basis der auf den Lebenszyklus wirkenden Einflussfaktoren”, Specht, D. (ed.), Gabler.

Ropohl, G. (1975), "Einleitung in die Systemtechnik”, Carl Hanser Verlag, München, Wien.

Saaty, T.L. and Vargas, L.G. (2006), "Decision Making with the Analytic Network Process Economic, Political, Social and Technological Applications with Benefits, Opportunities, Costs and Risks", Springer Science+Business Media.

Seram, N. (2013), "Decision Making in Product Development - A Review of the Literature", International Journal of Engineering and Applied Sciences, Vol. 2 No. 4.

Walch, M. and Albers, A. (2014), "Entscheidungsunterstützung bei der kunden- und anbietergerechten Konzeptentwicklung im Rahmen der Angebotsdefinition in der Anpassungs- und Variantenkonstruktion", Tagungsband, Vol. 12. Gemeinsames Kolloquium Konstruktionstechnik, Bayreuth, Germany. 